\title{
Chips in a crisis
}

\author{
The coronavirus pandemic and an increased demand for semiconductor technology has led to a global chip \\ shortage - and a re-evaluation of global supply chains.
}

ast month, we began an exploration of how Taiwan became a leading player in the global electronics industry. A variety of business models and suppliers are involved in the electronics industry, from integrated device manufacturers that design, fabricate and sell their own integrated circuits (ICs), to foundries that only manufacture ICs for others. And Taiwan's success can be linked, in part, to the pioneering role it played in the development of the foundry model. In a Comment article in this issue of Nature Electronics, the chairman of the Taiwan Semiconductor Manufacturing Company (TSMC), Mark Liu, recounts how the company - now the world's largest semiconductor foundry - broke the integrated device manufacturer mould in the mid-1980s and helped create the foundry model.

Taiwan's success is also one facet of the current dominance in semiconductor manufacturing of companies in Asia. Around $80 \%$ of global production is reported to now occur in Asia ${ }^{1}$, with Europe providing just under 10\% (down from around 44\% in $1990^{2}$ ) and the US just over $10 \%$. (The semiconductor industry in the US does though still account for almost $50 \%$ of the global sales market.) For many companies that rely on semiconductor components, a complex global supply chain is thus inevitable. But the outsourcing of manufacturing has delivered cost-efficient solutions and helped create a flexible ecosystem that can potentially adapt to changing consumer requirements. Recent events - the coronavirus pandemic, and a subsequent increase in demand for chips - have though disrupted these supply chains and we are currently in the midst of a global chip shortage ${ }^{3}$.

TSMC has said that it expects the chip shortage to last until $2022^{4}$. But even if the current chip crisis is relatively short-lived, emerging applications, such as autonomous vehicles, $5 \mathrm{G}$ communications and artificial intelligence, are likely to drive

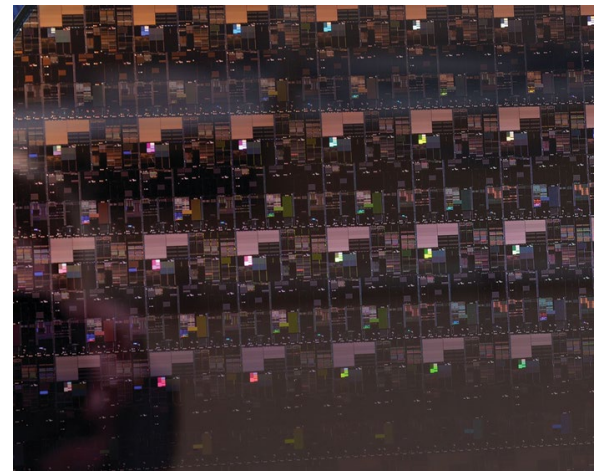

A $2 \mathrm{~nm}$ wafer fabricated at IBM Research's Albany facility. Credit: IBM.

further demand for semiconductors in the coming years. Geopolitical factors are also increasingly influencing semiconductor supply chains. The US has, for instance, placed export restrictions on China's largest chipmaker, Semiconductor Manufacturing International Corporation (SMIC) ${ }^{5}$.

As a result, there have been numerous calls to bolster domestic semiconductor manufacturing. The European Union has announced plans to diversify supply chains and improve industrial independence in the semiconductor sector ${ }^{6}$. It has also been in discussions with Intel, TSMC and Samsung Electronics about the creation of a European fabrication plant ${ }^{7}$. In the US, President Joe Biden has looked to strengthen domestic manufacturing and has proposed US $\$ 50$ billion for semiconductor research and manufacturing ${ }^{3}$. Intel has also recently announced that it will invest in two new fabrication plants in Arizona ${ }^{8}$. In South Korea, the government has revealed plans to establish the world's largest semiconductor supply chain - the K-semiconductor belt - by 2030 via investments totalling US $\$ 451$ billion, as well as tax breaks for chipmakers ${ }^{9}$. In China, the development of the domestic semiconductor industry has been a priority for a number of years and is part of the government's ten-year 'Made in China $2025^{\prime}$ plan $^{10}$.

Increasing any domestic manufacturing capacity will take time. Developing cutting-edge technology (the European Union proposals, for example, are aimed at a $2 \mathrm{~nm}$ technology node) is also ferociously expensive. IBM recently announced it had created a prototype $2 \mathrm{~nm}$ node chip ${ }^{11}$, but in terms of manufacturing, it is only TSMC and Samsung that currently offer chips at a leading $5 \mathrm{~nm}$ technology node. Such capabilities have been built on decades of investment and accumulated technical skills and know-how. The companies also continue to invest heavily in process technology research and development each year, and have access to the expensive lithography equipment required to advance IC technology. Expanding domestic semiconductor manufacturing - be it in Europe, the US, or China - will thus require a substantial and sustained commitment from all involved.

Published online: 25 May 2021

https://doi.org/10.1038/s41928-021-00601-0

References

1. 2020 State of the U.S. Semiconductor Industry (Semiconductor Industry Association, 2020); https://go.nature.com/3oeis8V

2. Drozdiak, N. Europe is trying to reclaim its lost chipmaking glory. Bloomberg (27 April 2021); https://go.nature.com/3y8sU6r

3. Clark, D. 'It's a roller-coaster ride': global chip shortage is making industries sweat. The New York Times (15 April 2021); https:// go.nature.com/2RbrcRc

4. Wu, D. TSMC lifts targets after warning chip crunch may hit 2022. Bloomberg (15 April 2021); https://go.nature.com/3uZpxNj

5. Strumpf, D. U.S. sets export controls on China's top chip maker. The Wall Street Journal (28 September 2020); https://go.nature. com/2QTTUpB

6. EU unveils plan to cut dependency on China, others. Reuters (5 May 2021); https://go.nature.com/33mcolb

7. Harper, J. The EU's microchip dilemma: too little or too late? $D W$ (29 April 2021); https://go.nature.com/3uuVflb

8. Intel CEO Pat Gelsinger announces 'IDM 2.0' strategy for manufacturing, innovation and product leadership. Intel News Release (23 March 2021); https://go.nature.com/3g4xsUP

9. Jaewon, K. South Korea plans to invest $\$ 450$ bn to become chip 'powerhouse'. Nikkei Asia (13 May 2021); https://go.nature. com/3fadiCM

10. Au, L. China is scrambling for semiconductor supremacy. Wired (29 April 2021); https://go.nature.com/2SGFuJK

11. IBM unveils world's first 2 nanometer chip technology, opening a new frontier for semiconductors. IBM News Room (6 May 2021); https://go.nature.com/3y3Iu34 